Ind. Health, 1966, 4,118.

\title{
METHOD FOR STUDIES ON INHALED PARTICLES IN HUMAN RESPIRATORY SYSTEM AND RETENTION OF LEAD FUME
}

\author{
Kosuke NOZAKI \\ National Institute of Industrial Health, Kizuki-Sumiyoshi, Kawasaki
}

(Received August 31, 1966)

\begin{abstract}
Method for the determination of retention of inhaled particles in the human respiratory tract was studied. Aerosol concentration was determined by light scattering, respiratory air flow by pneumotachograph, and carbon dioxide content by infrared analyzer (Capnograph). These were recorded simultaneously and continuously during breathing aerosol. Detector or parts of these measuring apparatus were inserted into the mouthpiece of which inner space was only $9.5 \mathrm{ml}$. This extreme reduction of the dead space of mouthpiece enabled the measuring apparatus to work with quick response. By this method, the retention of lead fume in the respiratory tract was studied. Lead fumes with various sizes from $0.05 \mu$ to $1 \mu$ were prepared by high frequency induction furnace. Total retention rate of lead fumes decreased with particle size, for instance, it was $63.2 \%$ for $1 \mu$ particle but $42.5 \%$ for $0.05 \mu$ at 10 respirations per minute. And the increase of respiratory rate resulted in the drop of retention. Retention rates in the upper and lower respiratory tracts were also determined.
\end{abstract}

\section{INTRODUCTION}

On the retention of inhaled particles in the human respiratory system the many works have been presented since Findeisen's theoretical calculation. 1 11)

Altshuler and others10) devised a new experimental procedure using Tyndallometer, infrared analyzer for carbon dioxide, and pneumotachograph.

In this study, the inhaled and exhaled aerosol concentrations were measured by the light scattering method developed by Koshi.12) And a measurement of air flow velocity during the respiration was carried out using the instrument which was devised to detect the small pressure difference by the author.13) These two devices and infrared analyzer for carbon dioxide (Capnograph, Godart) were assembled for the measurement of particle retention in the respiratory tract.

Detecting parts of these apparatus were arranged in the mouthpiece. And air space in the mouthpiece was devised to reduce as far as possible, to minimize the resulting error with the large dead space.

In addition to the study on the experimental method, retention of inhaled fume in the respiratory tract was also studied, as there had been few reports 


\section{INHALED PARTICLES IN HUMAN RESPIRATORY SYSTEM}

on the retention of lead fumes with various sizes.

\section{EXPERIMENTAL METHOD}

Assembly of apparatus is shown in Fig. 1. Apparatus assembly was composed of aerosol chamber (A), mouthpiece (M) to which aerosol detector, Capnograph, and pneumotachograph were attached. When the air was inhaled by a subject aerosol in the chamber was passed through the opened cocks $\left(\mathrm{C}_{2}\right)$, $\left(\mathrm{C}_{3}\right)$, opened valve $\left(\mathrm{V}_{1}\right)$, and then entered the respiratory tract.

Aerosol chamber. The chamber had a volume of 2251 and was made of acryl resin. Aerosols produced by various methods were introduced in this chamber through $\left(\mathrm{C}_{1}\right)$ and dispersed well by a fan (B). To control the concentration of aerosol in the chamber, fresh air which was freed from room dust by high efficiency ilter $\left(\mathrm{F}_{2}\right)$ was introduced in the chamber through (C). Pressure in the chamber was kept equally with outside pressure by free passing of air through the alter $\left(\mathrm{F}_{1}\right)$.

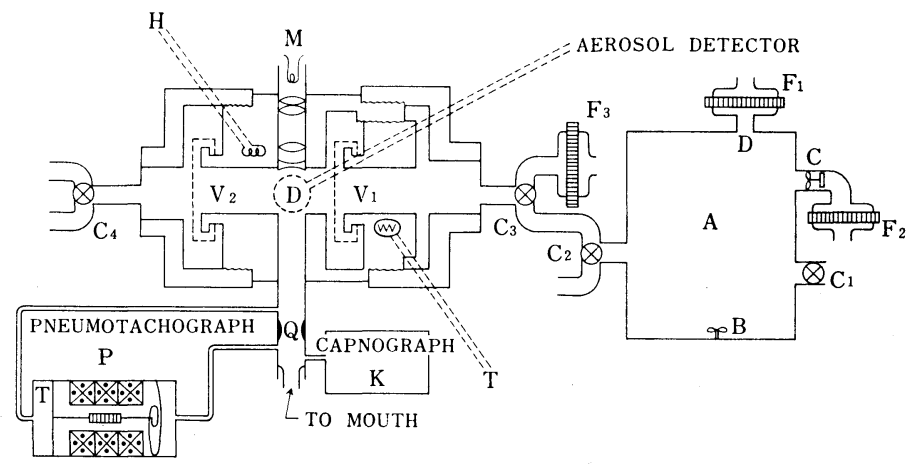

Fig. 1. Schematic diagram of apparatus for the measurement of aerosol retention on the human respiratory system.

Mouthpiece. Mouthpiece was made of brass and its inner surface was matted. The volume of inner space was $9.5 \mathrm{ml}$ including aerosol detector space of 4.5 m1. Rubber valve $\left(\mathrm{V}_{1}\right)$ was opend and $\left(\mathrm{V}_{2}\right)$ closed during inspiration, and $\left(\mathrm{V}_{1}\right)$ closed and $\left(\mathrm{V}_{2}\right)$ opend during expiration automatically. Aerosol concentration in the mouthpiece was determined at (D). As seen in (Y-Z) view of Fig. 2, the light from tungsten lamp (8 Volt, 5 Amp.) was passed in parallel beam at (D). The intensity of light scattered in the direction of $135^{\circ}$ to incident light by the suspended particles at (D) received by photomultiplier and transformed into an electric current. This current was recorded by the 6 channel recorder. This recorder also recorded simultaneously respiratory air flow and carbon dioxide content with aerosol concentration on the same paper.

Inspiratory and expiratory air movement were measured at (Q). Flow velocity was obtained by pneumotachograph utilizing the pressure difference before and after the orifice set at $(Q)$. Diameter of the orifice was changeable 


\section{K. NOZAKI}

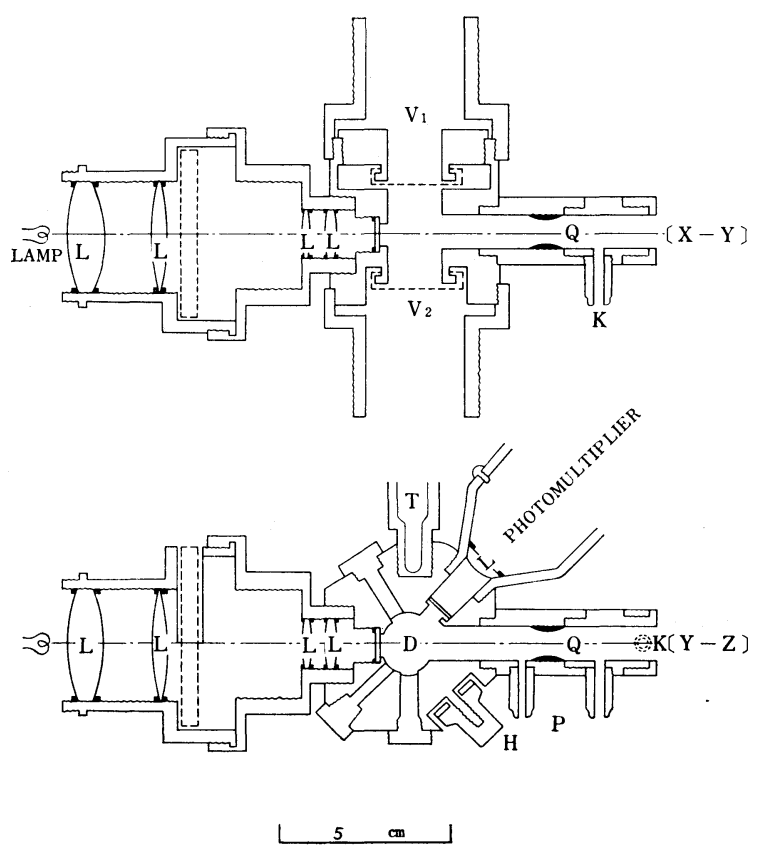

Fig. 2. Section of the mouthpiece.

according to air flow velosity. Pneumotachograph was composed of Teflon membrane $(T)$ which bended to the pressure difference at $(Q)$, ferrite core which was attached to the center of the membrane and differential transformer as shown Fig. 1. Pressure difference at $(Q)$ produced the bending of Teflon membrane and displacement of ferrite core in the differential transformer. Induced voltage was amplified and recorded.

The air for carbon dioxide determination was sampled at $(\mathrm{K})$, and led into an infrared carbon dioxide analyzer.

Air temperature in the mouthpiece was automatically controlled to be similar to the body temperature by a heater $(\mathrm{H})$ and a thermister $(\mathrm{T})$.

\section{Characteristics of the Apparatus}

Response of pneumotachograph. In order to examine the response of pneumotachograph artificial mechanical lung was used. Artificial mechanical lung, which was made by metal and could respire the air of $300 \sim 1500 \mathrm{~m} 1$ at $6 \sim 60$ respirations per minute $(\mathrm{rpm})$ by the displacement of piston in a cylinder, was connected to the mouthpiece. As seen Fig. 3, pneumotachograph showed a good correspondence to the respiratory air flow of artificial lung at 50 and $10 \mathrm{rpm}$ when the pattern of air movement was sine curve. Since pneumotachograph should response promptly and sharply to the change of flow direction, transient response of the detector to the air flow changing in rectangular wave form 


\section{INHALED PARTICLES IN HUMAN RESPIRATORY SYSTEM}

was tested. Results seemed to be satisfactory as seen in Fig. 4 (a).

A

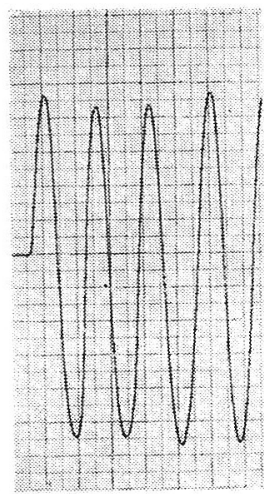

B

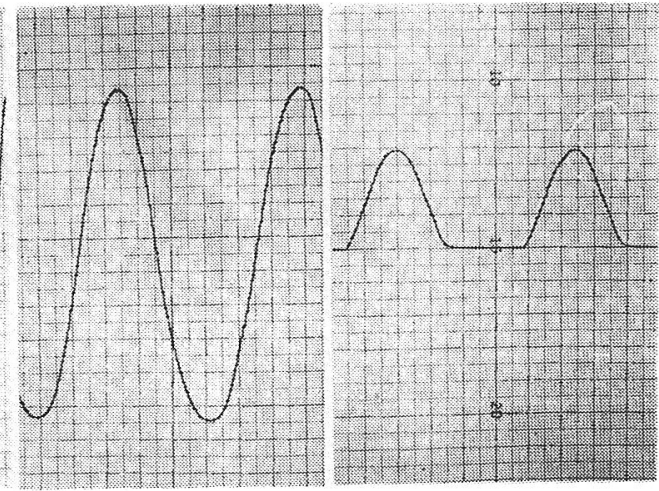

Fig. 3. Response of the pneumotachograph to air flow of artificial mechanical lung.

A: Respiratory flow curve when artificial lung respirated at $50 \mathrm{rpm}$.

B : Respiratory flow curve when artificial lung respirated at $10 \mathrm{rpm}$.

C : Expiratory flow curve when the artificial lung respirated at $10 \mathrm{rpm}$.

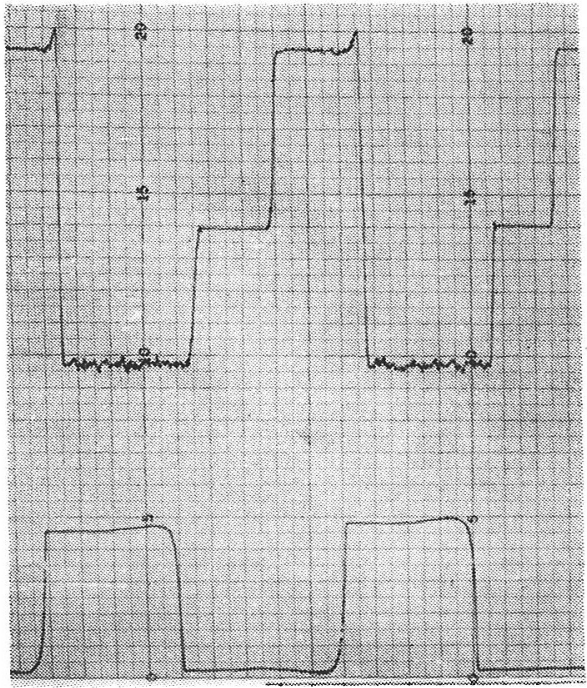

exp.

a

insp.

b

Fig. 4. Transient response of pneumotachograph and aerosol detector for rectangular wave form.

a: Velocity of air flow in the mouthpiece.

$\mathrm{b}$ : Aerosol concentration in the mouthpiece. 


\section{K. NOZAKI}

Response of aerosol detector. Response of aerosol detector to the change of aerosol concentration during respiration was examined by aerosol in the mouthpiece whose concentration was changed in rectangular wave form. Aerosol detector responded very quickly as seen in Fig. 4 (b).

Response of carbon dioxide analyzer. Response of carbon dioxide analyzer attached to the mouthpiece to the sharp change of carbon dioxide concentration was examined by alternative change of the flow of normal air and the air containing $6.3 \%$ carbon dioxide. To confirm the moment of flow change by pneumotachograph the normal air was bypassed before reaching the pneumotachograph, though it was aspirated into the carbon dioxide analyzer. Carbon dioxide analyzer showed a quick response to the change of carbon dioxide content as seen in Fig. 5. It responded with time lag of $0.7 \mathrm{sec}$. This time lag was assumed to be due to impedance matching of analyzer-amplifierrecorder system.

Determination of the retention rate. Aerosol concentration, air flow and carbon dioxide content of the inspired and expired air were recorded simultaneously as seen in Fig. 6. From this record, upper, lower and total retention were calculated.

In this report, distinction between the air expired from upper respiratory tract and from lower respiratory tract was made from the recorded carbon dioxide content in the expired air. As seen in Fig. 6, carbon dioxide content increased rapidly after the start of expiration and then very gradually. It was not a so difficult work to find out the point of infiection between the rapid increase and gradual increase, and the expired air before the inflection point was designated as the air from upper respiratory tract and the air after that point as from lower respiratory tract. Air volumes from the upper and the lower respiratory tract were determined respectively from the air flow curve corresponding to carbon dioxide curve, and the aerosol concentration in each part was calculated from the air flow and aerosol concentration curves.

Upper and lower respiratory retention rate were obtained as follows.

Upper respiratory retention rate $=\left(I_{u}-E_{u} / I\right) \times 100$

Lower respiratory retention rate $=\left(I_{l}-E_{l} / I\right) \times 100$

$I_{u}$ : Amount of aerosol inhaled into the upper respiratory tract.

$I_{l}$ : Amount of aerosol inhaled into the lower respiratory tract.

$E_{u}$ : Amount of aerosol exhaled from upper respiratory tract.

$E_{l}$ : Amount of aerosol exhaled from lower respiratory tract.

$I$ : Amount of aerosol in the inspired air.

Total respiratory retention rate was calculated from the following equation.

Total retention rate $=\left(1-E_{t} / I\right) \times 100$

$E_{t}$ : Amount of aerosol in the total exhaled air.

Amount of aerosol in the total exhaled air $E_{t}$ was obtained by $E_{u}+E_{l}$. 


\section{INHALED PARTICLES IN HUMAN RESPIRATORY SYSTEM}

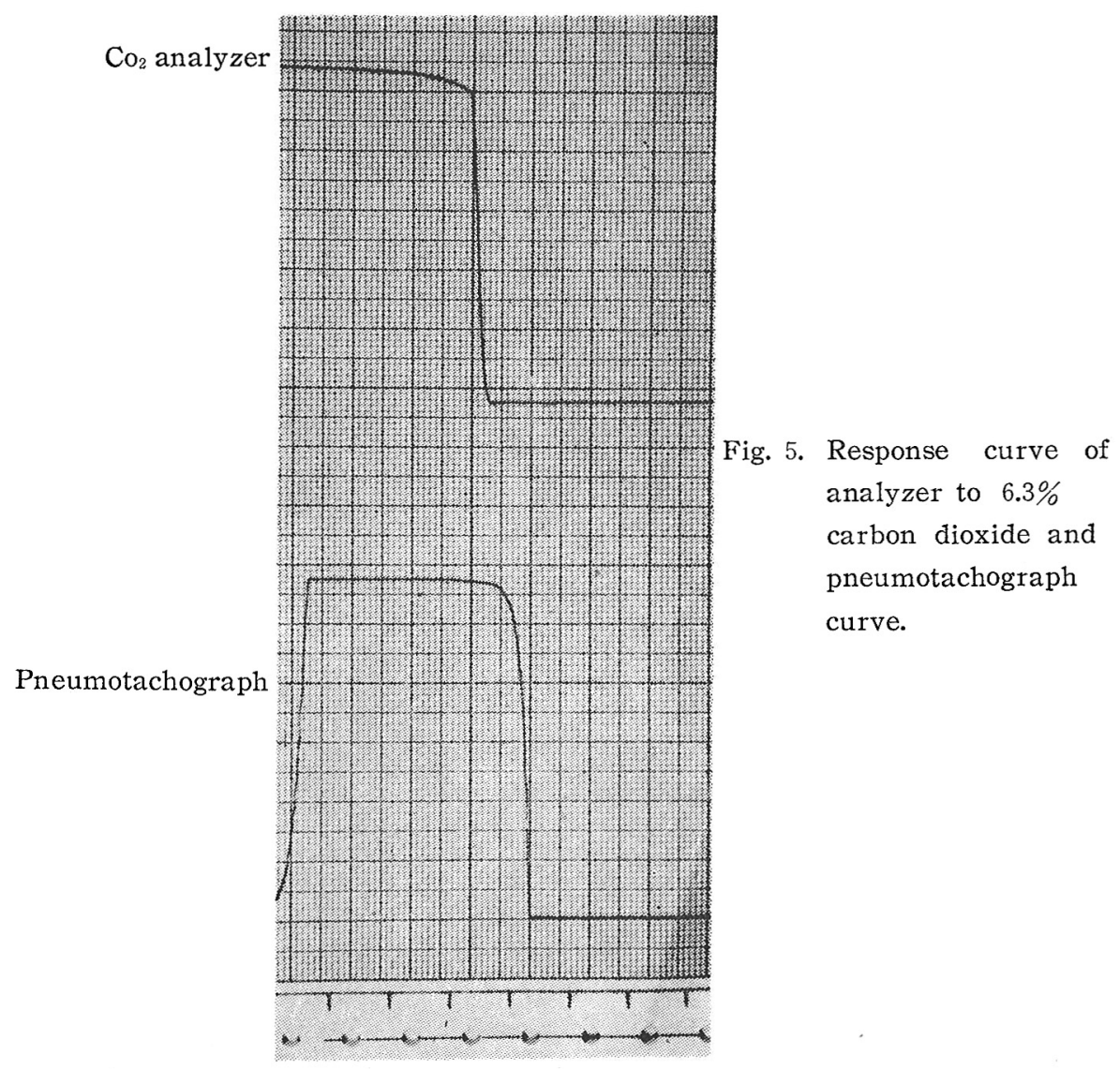

The amount of aerosol was calculated by multiplying the aerosol concentration by period of respiration.

\section{LeAd Fume Retention in the Respiratory Tract}

\section{a) Experimental Procedure}

Seven samples of aerosol containing lead fume of $1.0,0.6,0.4,0.2,0.1$, 0.08 , and $0.05, \mu$ in mean size were produced by high frequency induction furnace. Preparing method will be reported by K. Homma. Each aerosol was introduced into the aerosol chamber, and the concentration was kept to be 10 $\mathrm{mg} / \mathrm{m}^{3}$ as far as possible during the experiment. The air containing lead fume was inhaled through the mouth by the author (male, 32 years old). Respiratory rates were 10 and $30 \mathrm{rpm}$ (respirations per minute) and controlled by metronome. After the subject was adapted to each respiratory rate by breathing fresh air, lead fume was inhaled, and the aerosol concentration, air flow and carbon dioxide content were recorded simultaneously. Inhalation experiments were carried out at least twice on each particle size and respiratory rate.

Upper, lower and total respiratory retention rates for lead fumes were calculated on seven sizes and two types of respiration from the recorded data excluding initial and final three breathes. Considering the aggregation of 


\section{K. NOZAKI}

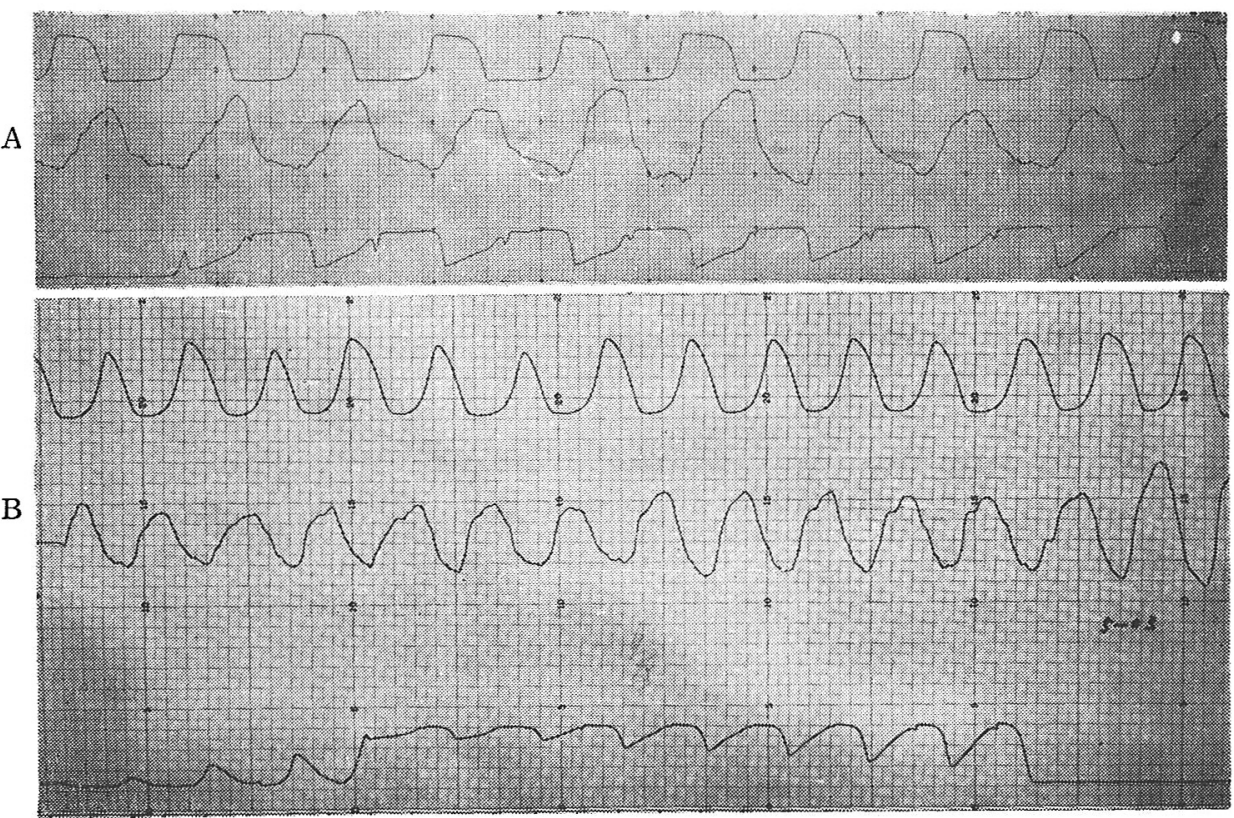

Fig. 6. An example of obtained data.

A : Respiration rate $10 \mathrm{rpm}$, mean particle size $0.05 \mu$.

B : Respiration rate $30 \mathrm{rpm}$, mean particle size $0.05 \mu$.

Top curve - carbon dioxide content, middle curve - respiratory flow velocity curve, bottom curve-aerosol concentration.

Table 1. Experimental results of retention rate and characteristics of respiration.

\begin{tabular}{|c|c|c|c|c|c|c|c|c|c|}
\hline \multirow{3}{*}{$\begin{array}{c}\text { Particle } \\
\text { size of } \\
\text { lead } \\
\text { fume } \\
(\mu)\end{array}$} & \multirow{3}{*}{$\begin{array}{l}\text { Respira } \\
\text {-tory } \\
\text { rate } \\
(\mathrm{RPM})\end{array}$} & \multirow{3}{*}{$\begin{array}{l}\text { Time of } \\
\text { respira- } \\
\text { tion } \\
(\mathrm{sec})\end{array}$} & \multirow{3}{*}{$\begin{array}{c}\text { Tidal } \\
\text { air } \\
\text { volume } \\
\text { (cc) }\end{array}$} & \multirow{3}{*}{$\begin{array}{c}\mathrm{CO}_{2} \\
\text { content } \\
(\%)\end{array}$} & \multirow{3}{*}{$\mid \begin{array}{c}\text { Total } \\
\text { retention } \\
(\%)\end{array}$} & \multicolumn{4}{|c|}{ Regional retention } \\
\hline & & & & & & \multicolumn{2}{|c|}{$\begin{array}{c}\text { Upper } \\
\text { respiratory }\end{array}$} & \multicolumn{2}{|c|}{\begin{tabular}{|c|} 
Lower \\
respiratory
\end{tabular}} \\
\hline & & & & & & $\begin{array}{l}\text { air vol. } \\
\text { (cc) }\end{array}$ & $\begin{array}{c}\text { retention } \\
(\%)\end{array}$ & $\begin{array}{l}\text { air vol. } \\
\text { (cc) }\end{array}$ & $\begin{array}{c}\text { retention } \\
(\%)\end{array}$ \\
\hline 1 & \multirow{7}{*}{10} & \multirow{7}{*}{6} & \multirow{7}{*}{1350} & \multirow{7}{*}{4.2} & 63.2 & \multirow{7}{*}{400} & 28 & \multirow{7}{*}{950} & 36 \\
\hline 0.6 & & & & & 59.0 & & 29 & & 30 \\
\hline 0.4 & & & & & 50.9 & & 26 & & 25 \\
\hline 0.2 & & & & & 48.1 & & 26 & & 22 \\
\hline 0.1 & & & & & 39.3 & & 14 & & 25 \\
\hline 0.08 & & & & & 40.0 & & 14 & & 26 \\
\hline 0.05 & & & & & 42.5 & & 6 & & 37 \\
\hline 1 & \multirow{7}{*}{30} & \multirow{7}{*}{2} & \multirow{7}{*}{450} & \multirow{7}{*}{4.2} & 35.5 & \multirow{7}{*}{250} & 5 & \multirow{7}{*}{200} & 31 \\
\hline 0.6 & & & & & 33.5 & & 5 & & 28 \\
\hline 0.4 & & & & & 33.0 & & 3 & & 30 \\
\hline 0.2 & & & & & 29.9 & & 3 & & 27 \\
\hline 0.1 & & & & & 27.9 & & 2 & & 26 \\
\hline 0.08 & & & & & 26.5 & & 2 & & 25 \\
\hline 0.05 & & & & & 21.0 & & 2 & & 19 \\
\hline
\end{tabular}




\section{INHALED PARTICLES IN HUMAN RESPIRATORY SYSTEM}

particles in the respiratory tract, lead fumes in the inhaled and exhaled air were collected by a jet dust counter, and examined by electron microscope.

\section{b) Results}

Results are shown in Table 1 and Fig. 7. In the respiratory rate of $10 \mathrm{rpm}$, total retention rate dropped gradually with the decrease of particle size down to $0.1 \mu$, but it rised with the decrease of particle size below $0.1 \mu$. Therfore, minimum total retention was found at $0.1 \mu$. In $30 \mathrm{rpm}$, total retention rate dropped with size reduction and no minimum value was found in the size

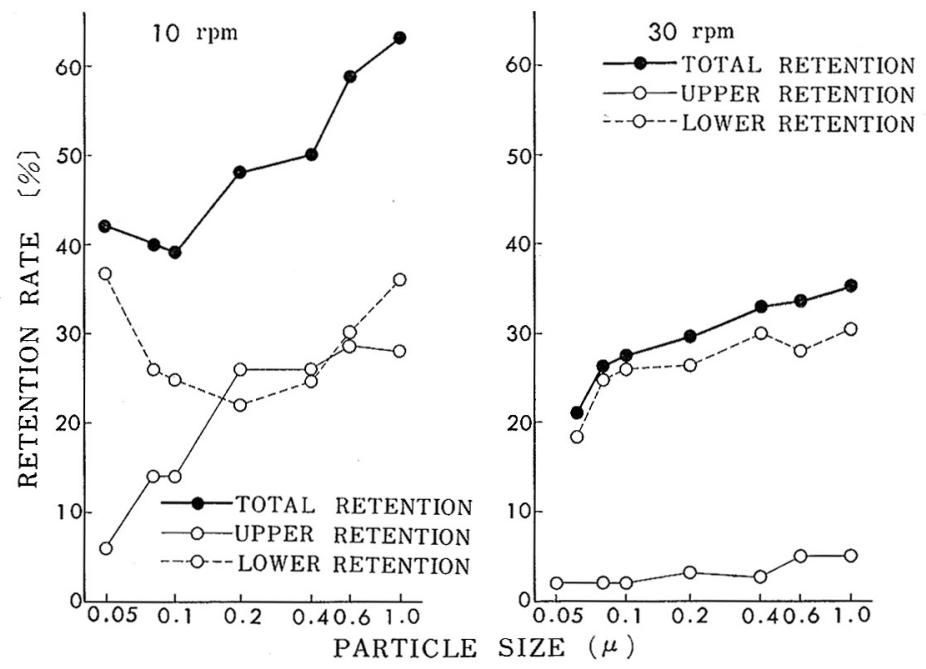

Fig. 7. Relation between particle size and retention rate, total and regional retention for respiration rate.
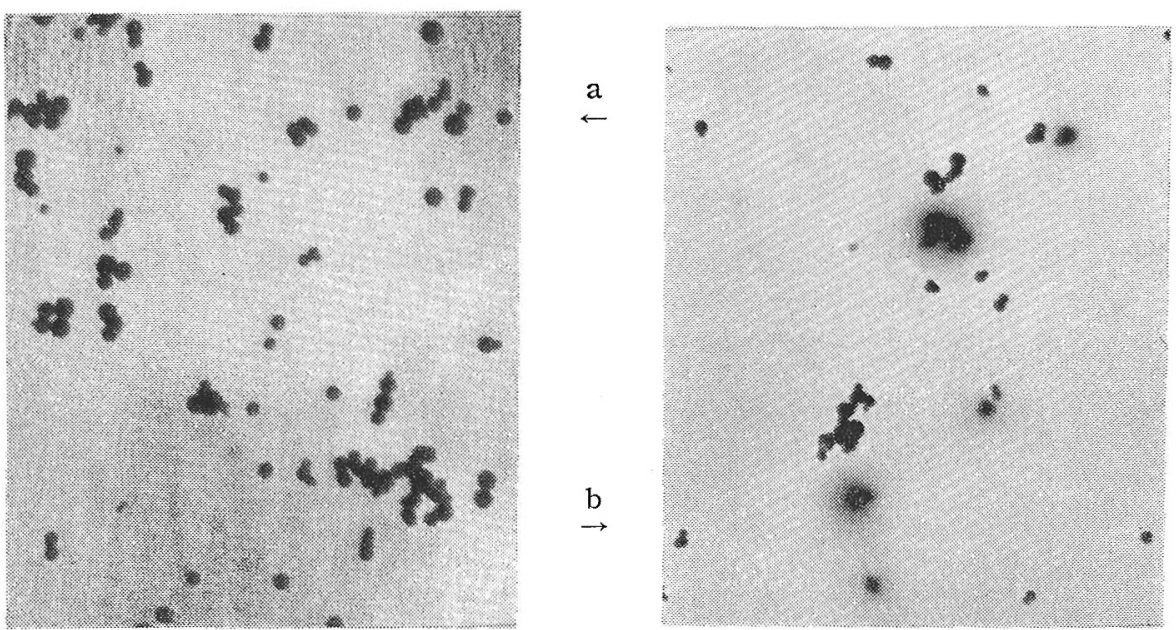

Fig. 8. Electron micrographs of lead fume. $(\times 20000)$

a: Lead fume in the inspired air.

$\mathrm{b}$ : Lead fume in the expired air. 


\section{K. NOZAKI}

range used in this experiment.

Upper respiratory retention dropped with the decrease of particles size in both respiratory rates, though more marked decrease was observed in $10 \mathrm{rpm}$. The most marked difference between the two respiratory patterns was that the retention rate was too small in $10 \mathrm{rpm}$ as compared with $30 \mathrm{rpm}$, and for instance, retention of lead fume of $1 \mu$ size was only $5 \%$ in the former compared with $28 \%$ in the latter. On the lower respiratory retention, the minimum value was found at $0.2 \mu$ in $10 \mathrm{rpm}$, but in $30 \mathrm{rpm}$ the retention rate dropped with particle size reduction without showing any minimum value.

Electron micrographs of lead fumes were shown in Fig. 8. As seen in the figure, the size distribution of lead fume was rather skew, and exhaled particles were not so much aggregated.

\section{DISCUSSION}

In the studies on the aerosol retention in the pulmonary tract air space of the mouthpiece or the space for various determinations should be very small, since air space becomes to constitute a part of respiratory tract. Air space of the mouthpiece used in this study was $9.5 \mathrm{ml}$ and it seemed to be small enough as compared with about $20 \mathrm{ml}$ of the volume of mouth or pharynx.

Detecting parts of the aerosol detector, pneumotachograph, and carbon dioxide detector were inserted in this small air space. The pneumotachograph utilizing a differencial transformer had the advantages to have small detector part and quick response to flow change.

Many theoretical and experimental studies have been reported on the retention of particles in the respiratory tract, but the studies on heavy particles such as lead were rare.

Homma has studied on the producing method of metal fume of various sizes, and his method was used to prepare the lead fume in this study.

Deposition or retention of the particle in the respiratory tract depends on settlement by gravity, impaction by inertia, and diffusion. Findeisen's calculation has been confirmed by many experimental studies. Hatch summarized these data by equivalent impaction diameter $\sqrt{\sigma d^{2}}$ of particles. Many experimental studies showed the minimum retention equivalent to impaction diameter of 0.3 to $0.5 \mu$ in the total and pulmonary retention. Retention curves calculated by transforming project diameter of lead fume into equivalent impaction diameter did not agree well with the retention curves summarized by Hatch. In the lower respiratory retention of lead fume in $10 \mathrm{rpm}$, inertia seemed to be not so infuential but diffusion and sedimentation to be main factors controlling the retention. Fig. 9 shows the displacement distances of particles of various sizes by difiusion and sedimentation, and the cross point of two curves 


\section{INHALED PARTICLES IN HUMAN RESPIRATORY SYSTEM}

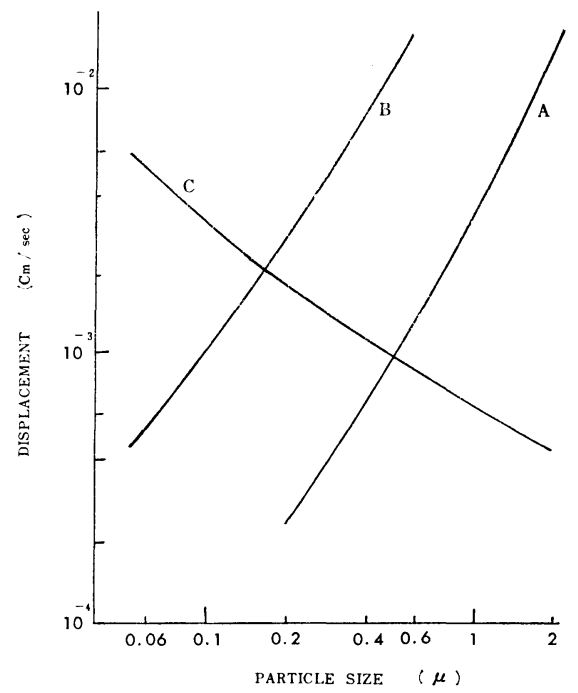

Fig. 9. Relation between the displacement of particle and particle size, for the Brownian motion and terminal velocity by the spheres particle. $\left(\mathrm{sec}^{-1}\right)$.

A : Sedimentary displacement for settling effect by the spheres of unit density, at $20^{\circ} \mathrm{C}$ ane $760 \mathrm{mmHg}$.

B : Sedimentary displacement for settling effect by the lead fume (d $=11.34$ ), at $20^{\circ} \mathrm{C}$ and $760 \mathrm{mmHg}$.

C: Displacement of mean free pass for Brownian motion, at $20^{\circ} \mathrm{C}$ and $760 \mathrm{mmHg}$.

was found at the particle size of $0.18 \mu$. The minimum value at $0.1 \mu$ in the lower respiratory retention in $10 \mathrm{rpm}$ might be explained by the settlment and diffusion, but the reason why such minimum value was not found in $30 \mathrm{rpm}$ was obscure.

Slow air movement, small tidal air volume and wide respiratory tract seemed to reduce the effect of impaction and settlement to the particle deposition. These consideration might suggest the causes of low deposition rate in upper respiratory tract and absence of minimum value in lower respiratory retention in $30 \mathrm{rpm}$.

Mechanism by which particles reached very deep respiratory tract seemed to differ according to the respiratory pattern, and this might explain the different retention pattern between $10 \mathrm{rpm}$ and $30 \mathrm{rpm}$. Cause of lower retention rate in upper respiratory tract in $30 \mathrm{rpm}$ might be explained by the weak influence of diffusion and settlement to the particles, since the retaining time of particles in the respiratory tract was short. After the inhalation of lead fume the subject were respirated with fresh air, and the lead particle concentrations in the expire air were examined. In $30 \mathrm{rpm}$ exhaled lead fume was found in considerable amount at first and decreased very gradually but no lead fume was exhaled in $10 \mathrm{rpm}$. This fact might be explained by the 


\section{K. NOZAKI}

small tidal volume in frequent respirations and the experimental condition that the respiratory pause was not inserted in each respiratory cycle. In 30 $\mathrm{rpm}$, it was assumed that the inhaled air could not reach the very deep respiratory tract, and the inhaled lead particles entered into this part only by difiusion. Perhaps, the particles suspended in the region of still air would be exhaled gradually in the successive expirations after the inhalation of fume. In order to understand the interpulmonary retention of heavy and very small particles, theoretically fundamental experimental studies should be carried out.

\section{REFERENCES}

1) Findeisen, W. (1935). Pfluger Arch. f.d.ges. Physiol., 236, 367.

2) Van wijk, A. M. and Patterson, H. S. (1940). J. Ind. Hyg. Toxicol., 22, 31.

3) Landahl, H. D. and Hermann,R.G. (1948). J. Ind. Hyg. Toxicol., 30, 181.

4) Landah1, H. D. (1950). Bul. Math. Biophysics, 12, 43.

5) Landah1, H. D. (1950). Bul. Math. Biophysics, 12, 161.

6) Brown, J. H., Cook, K. M., Ney, F. G. and Hatch, T. (1950). Am. J. Public Health, 40, 450.

7) Landah1, H.D., Tracewell, T. N. and Lassen, W. H. (1951). A. M. A. Arch. Ind. Hyg. Occupational Med., 3, 359.

8) Landahl, H. D., Tracewell, T. N. and Lassen, W. H. (1952). A. M. A. Arch. Ind. Hyg. Cccupational Med., 6, 508.

9) Dautrebande, L., Beckmann, H., and Walkenhorst, W. (1957). A. M. A. Arch. Ind. Health., 16, 179.

10) Altshuler, B., Yarmous, L., Palmes, E. D. and Nelson, N. (1957). A. M. A. Arch. Ind. Health, 15, 293.

11) Morrow, P. E., Mehrhof, E., Casarett, L. J., and Morken, D. A. (1958). A. M. A. Arch. Ind. Health, 18, 292.

12) Koshi, S. (1960). Bull. Nat. Inst. Ind. Health, 3, 23.

13) Nozaki, K. (1965). Ind. Health, 3, 64. 